\title{
Brustkrebs: schwaches Bild beim „starken Geschlecht“
}

Männer mit Brustkrebs haben es schwer. Bei „nur" etwa 600 Betroffenen, die jährlich in Deutschland erkranken, sind selbst viele Ärzte ratlos, wann und wie nach einer Diagnose vorzugehen ist. Zudem geht die Diagnose Brustkrebs bei Männern meist mit einem noch größeren Schock einher als bei Frauen. Hafte der Tumorart doch das Stigma der "typischen Frauenerkrankung" an, so Nicole Ernstmann von der Forschungsstelle für Gesundheitskommunikation und Versorgungsforschung an der Klinik und Poliklinik für Psychosomatische Medizin und Psychotherapie des Universitätsklinikums Bonn. Zusammen mit der Universitätsklinik Köln, dem Brustzentrum des Klinikums der Universität München und dem Bereich Zertifizierung der Deutschen Krebsgesellschaft (DKG) starten die Bonner nun das Projekt "N-MALE“. Ziel ist es, die medizinischen und psychosozialen Bedürfnisse von männlichen Brustkrebspatienten genauer zu untersuchen. Die Rekrutierung von Patienten erfolgt über zertifizierte Brustkrebszentren. Ansprechpartner für Patienten, die Interesse an einer Studienteilnahme haben, ist Sarah Halbach (sarah.halbach@ukb.uni-bonn.de).

Martin Roos

\section{Problem Abrechnung}

Wie die "Süddeutsche Zeitung" am 25.4.2016 auf ihrer Titelseite hervorhob, gelten für die $\mathrm{Ab}$ rechnung der Behandlung von männlichen Brustkrebspatienten keine einheitlichen Regeln:

_ In Westfalen müssen sich Gynäkologen um Ausnahmegenehmigung bei der Kassenärztlichen Vereinigung bemühen.

_ In Hessen dürfen Gynäkologen zu $3 \%$ Männer behandeln.

_ In Hamburg können Gynäkologen problemlos abrechnen.

_ In Baden-Württemberg dürfen Gynäkologen nach der Petition eines Patienten jetzt uneingeschränkt behandeln.

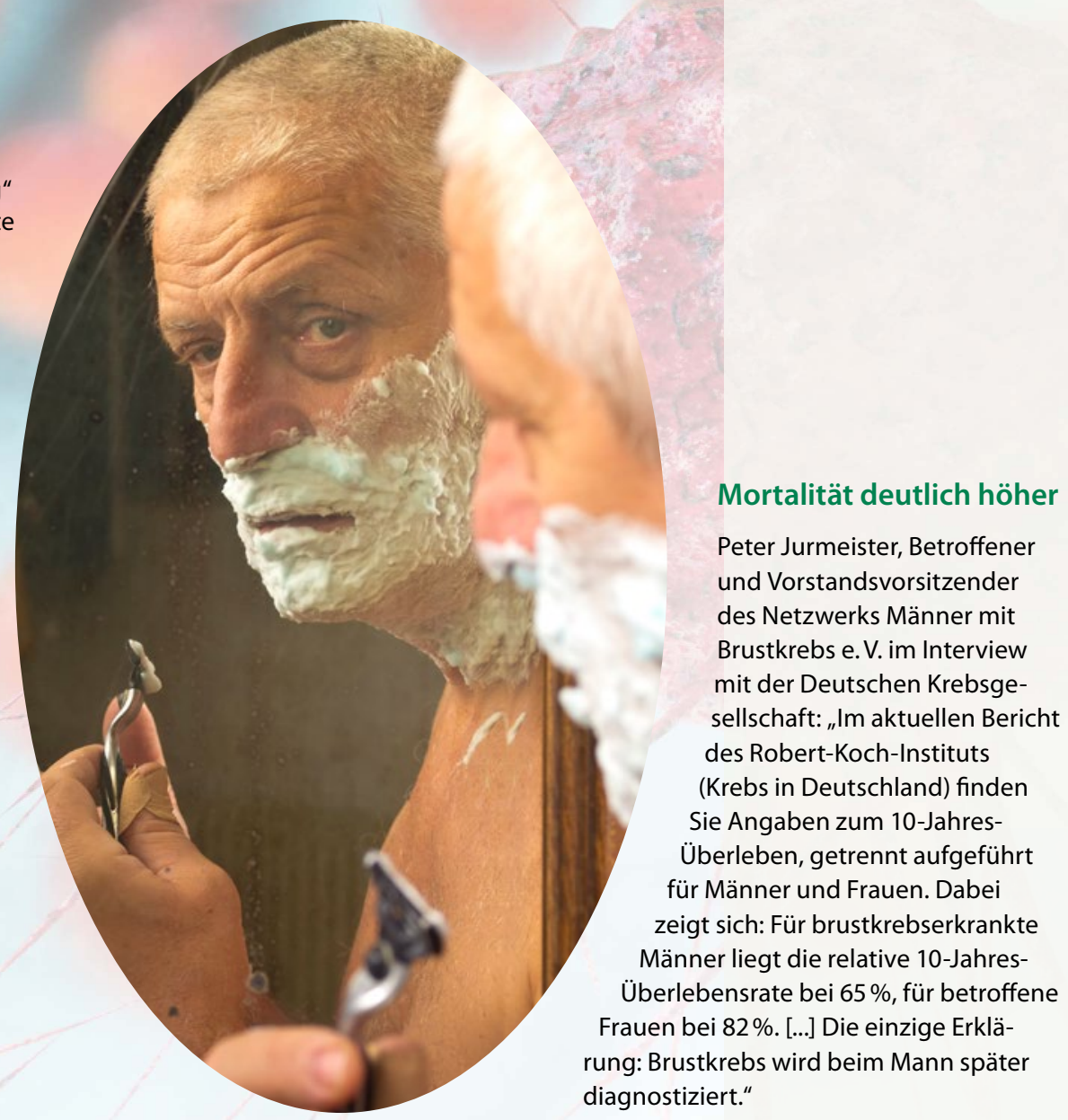

